\title{
Unannounced Quizzes: A Teaching and Learning Initiative that Enhances Academic Performance and Lecture Attendance in Large Undergraduate Classes
}

\author{
Mrs Evelyn Derera \\ School of Management, IT \& Governance, P Bag X01, Scottsville, Pietermaritzburg, \\ University of KwaZulu-Natal, South Africa \\ Email:dererae@ukzn.ac.za \\ Dr Micheline Naude \\ School of Management, IT \& Governance, P Bag X01, Scottsville, Pietermaritzburg, \\ University of KwaZulu-Natal, South Africa \\ Email: naudem@ukzn.ac.za
}

\section{Doi:10.5901/mjss.2014.v5n20p1193}

\begin{abstract}
Without a doubt, lecture non-attendance is a growing trend at tertiary institutions. Many academics confront this challenge by implementing different teaching initiatives that encourage lecture attendance. However, lecture attendance does not necessarily mean that learning is taking place. Therefore, the aim of this study was to establish whether the use of unannounced quizzes improves class attendance, the module pass rate and academic performance in a large undergraduate class at a university in South Africa. This is an exploratory study which adopted a mixed method research approach to collect data over a period of two semesters during the 2012 academic year. The three data sources used include observations, a questionnaire survey and the university student data base. Descriptive statistics and content analysis were used to analyse data. The findings reveal that the use of unannounced quizzes has merit; significant positive effects were seen in all three areas - class attendance, module pass rate and students' academic performance. The study contributes to the field of teaching and learning in three ways, by: (1) exploring a teaching and learning initiative that encourages class attendance; (2) responding to a call for new thinking about how universities could increase their throughput ratio; and (3) possibly reviving future debate about how to effectively impact knowledge creation in a large class situation.
\end{abstract}

Keywords: teaching and learning; large classes; unannounced quizzes; higher education practices.

\section{Introduction}

The quality and level of education acquired by students can be seen to impact on their contribution to national development. In many countries, education is viewed as an agent that promotes survival; the reason why so many countries invest significant resources in education (Tella, 2007). "Education has long been recognized as a route out of poverty and a way of promoting equal opportunities" (Nzimande, 2014:3). South Africa is no exception. The government of South Africa is committed to the development of education in the country. "Education has been a priority of government and has been the largest item on its budget over many years" (EFA, 2013:58). For example, the education budget was raised by 12\% from ZAR207 billion in 2012 to ZAR232 billion in the 2013 budget, of which ZAR28 billion was set aside specifically for higher education (Butler-Adam, 2013). The 12\% budget increase represented a real increase of about $6 \%$, which shows the government's commitment to this cause (Butler-Adam, 2013).

Despite the government's investment in Higher Education, the country's undergraduate graduation rate of $15 \%$ is one of the lowest in the world (Department of Education, 1999), with the corresponding drop-out rate being as high as $80 \%$ (HSRC, 2008). This high drop-out rate is costing the National Treasury approximately R4.5 billion in grants and subsidies and results in the level of risk not being commensurate with the return on investment in education (HSRC, 2008). Therefore, "student retention and success is a major concern among higher education systems, institutions and institutional researchers worldwide" (Visser \& van Zyl, 2013).

Given the high demand for higher education and the phenomenon of educational expansion worldwide, large classes have become a part of the teaching setup at universities, particularly at undergraduate level. The reality is that most undergraduate classes at South African public universities are large. Teaching large classes presents a special 
challenge for academics at institutions of higher learning, not only in South Africa, but also across the globe. This challenge is compounded by poor attendance of lectures by university students. According to Massingham and Herrington (2006), non-attendance of lectures appears to be a growing trend at universities. Many academics are confronting this challenge by planning and implementing different teaching and learning initiatives that encourage lecture attendance. This is because academics perceive that students benefit from attending classes, hence resulting in improved academic performance (e.g. Rodgers, 2002). However, according to Rodgers (2002), lecture attendance does not necessarily mean that learning is taking place. Physical presence and intellectual involvement are two different and separate phenomena (Rodgers, 2002). It is becoming increasingly important to find ways of ensuring that effective learning takes place through actively engaging with students.

Some of the mostly widely used initiatives include unannounced quizzes, allocation of marks for class participation and penalizing students for non-attendance of lectures. These initiatives are usually linked to students' final module marks (Rodgers, 2002). For example, in a study by Rodgers (2002), students were penalized for missing two tutorials without a valid reason by deducting $1 \%$ from the final mark. Such initiatives were found to have a significant positive impact on class attendance (Devadoss \& Foltz, 1996; Rodgers, 2002).

Although some academics are using these initiatives, compulsory lecture attendance is difficult to enforce (Rodgers, 2002) because it often leads to tension between academics and students over the right to exercise personal freedom. This is due to the fact that a university is generally regarded as a "rite of passage for its students and is regarded as the coming of age and the development of autonomous adults" (Leufer \& Cleary-Holdforth, 2010:18.1). Hence, there is little evidence of university policies that enforce lecture attendance (Cleary-Holdforth, 2007; Leufer \& Cleary-Holdforth, 2010), yet training and education is central to the university and its 'contact' modules. Thus, university policy on compulsory lecture attendance often does not exist, except in certain instances where there is a professional element linked to the module, for example in nursing (Leufer \& Cleary-Holdforth, 2010).

Past research focused on the relationship between class attendance; class participation and students' performance (e.g. Devadoss \& Foltz, 1996; Gatherer \& Manning, 1998; Rodgers, 2002; Van Walbeek, 2004; Massingham \& Herrington, 2006; Nyamapfene, 2010). Most of these studies show a positive relationship between class attendance; class participation and students' performance (e.g. Rodgers, 2002; Nyamapfene, 2010). However, previous research concentrated on modules offered in various disciplines other than business management. These disciplines include: macroeconomics (Stanca, 2006); biology (Gatherer \& Manning, 1998); introduction to statistics (Rodgers, 2002); and Mathematics (Jungic, Kent \& Menz, 2006). With regard to the use of unannounced quizzes as an initiative to encourage class attendance, the literature is almost silent on the details of how such quizzes influence class attendance, as well as information on and students' perceptions of this initiative for a second year business management module.

Against this background, this study explores whether the use of unannounced quizzes as a teaching and learning initiative enhances class attendance and improves academic performance, as well providing information on the students' perception thereof, at the University of KwaZulu-Natal, South Africa. More specifically, the research objectives are:

1. to establish whether the use of unannounced quizzes enhances class attendance;

2. to examine the relationship between class attendance and module pass rate; and

3. to explore students' perceptions of the use of unannounced quizzes as a teaching and learning initiative.

This article contributes to the field of teaching and learning in three ways. Firstly, it explores a teaching and learning initiative that encourages class attendance among university students in the modern day of technology. Secondly, this study responds to the call for new thinking about how universities could increase their throughput ratio, especially in South Africa, where students struggle to complete their qualifications within the required time period. Lastly, the findings of this research are expected to revive future debate on how to effectively impact knowledge in a large class situation, especially in developing economies such as South Africa where the university dropout rate due to failure remains high.

This paper consists of five parts: (1) background to the university where the study took place - University of KwaZulu-Natal; (2) a review of existent literature on teaching large classes and various teaching and learning initiatives that are used; (3) the research methodology; (4) the analysis of the results; and (5) concluding remarks that include the limitations of this study and recommendations for future research.

\section{Background of the University of KwaZulu-Natal}

The University of KwaZulu-Natal was formed on 1 January 2004 as a result of the merger between the University of Durban-Westville and the University of Natal. The merger was in accordance with the government's higher educational restructuring plans which aimed at reducing the number of higher educational institutions in South Africa from 36 to 21 
(UKZN, n.d.). The mergers resulted from a wide-ranging consultative process on the restructuring of the Higher Education Sector that began in the early 1990s and was confirmed by a Cabinet decision in December 2002 (Ministry of Education, 2002). One of the goals of the National Plan for Higher Education was to "build new institutional identities and organizational forms through restructuring the institutional landscape of the higher education system, thus transcending the fragmentation, inequalities and inefficiencies of the apartheid era" (Ministry of Education, 2002: 5; Gillard, Saunders, Terblanche and Sukel, 2012: 4).

The University of KwaZulu-Natal has five campuses. Three of the campuses are based in Durban and these are: Westville Campus (which houses the office of the Vice-Chancellor, the offices of Executive members and University-wide administrative divisions); Howard College; and the Medical School. The other two campuses are Edgewood Campus (based in Pinetown) and Pietermaritzburg Campus (based in Pietermaritzburg).

The study took place in the School of Management, Information Technology and Governance at Pietermaritzburg campus during the 2012 academic year. It was motivated by the fact that the module pass rate for an undergraduate second year management module had decreased from $69.63 \%$ to $41.38 \%$ during the second semester of 2011. Additionally, this period was characterized by poor attendance of lectures by students. As a result, unannounced quizzes were adopted as a teaching and learning initiative to encourage students to attend lectures and to improve the module pass rate.

\section{Literature Review}

\subsection{What constitutes a large class?}

Teaching large classes is not a new phenomenon (Rodgers, 2002; Massingham \& Herrington, 2006), and this issue will always be a feature in tertiary education. There is ongoing debate surrounding what exactly constitutes a "large class" at tertiary level. While the issue of teaching large classes at tertiary level has been extensively researched, Biggs (1999) argues that it is difficult to determine the constitution of a "large" class in a tertiary level education context or a class that is too large for effective teaching to take place. A more comprehensive definition includes other factors such as, the nature of the course, the facilities, venues and resources needed (Biggs, 1999). In many countries like the United States, France, Holland and Italy, class sizes range from 300 to 1000 students (Mulryan-Kyne, 2010). South African universities are no exception as large classes are common for first and second year compulsory modules. For example, for institutions that focus on open distance learning and e-learning, a large class is made up of several thousands of students (Weller, 2004). The average class size at the University of KwaZulu-Natal falls within the range proposed by MulryanKyne (2010) and at times, a class size at the Westville Campus, could exceed 1000 students.

Regardless of class size, the underlying issue is that teaching a large class is difficult because of a number of challenges. A large body of literature focused on the challenges and opportunities of teaching large classes (e.g. Jungic et al., 2006; Mulryan-Kyne, 2010; Mahadeo, 2012). One major challenge associated with teaching large classes is dealing with a student population that is diverse in age, experience, cultural background and socio-economic status (Mulryan-Kyne, 2010). Other related challenges include: the limited interaction between the lecturer and the students; poor attendance; and the need for advanced classroom management skills. This is in line withBiggs (1999) argument that teaching and learning standards could be compromised in a large class situation. Thus, a need is created for tertiary institutions to recruit competent lecturers who are able to instruct at tertiary education level regardless of the class size (Mulryan-Kyne, 2010).

\subsection{Initiatives to encourage lecture attendance}

Given that absenteeism is common and that it is believed that absenteeism impedes performance, it is worthwhile to consider initiatives to encourage students to attend lectures. A large body of literature agrees that lecture attendance impacts positively on performance (Rodgers, 2002; Massingham \& Herrington, 2006; Nyamapfene, 2010). While it is difficult to enforce compulsory class attendance for large classes, various types of initiatives could be introduced to discourage absenteeism. Devadoss and Foltz (1996) agree that such initiatives have a significant, positive impact on class attendance. These initiatives include unannounced quizzes, marks allocated for class participation and penalizing students for non-attendance of lectures (Rodgers, 2002). Penalizing students for failure to attend lectures sounds unfair because at times students do not attend lectures for genuine reasons, for example, illness. In this regard, students should be encouraged to attend at least $80 \%$ of the lectures and failure to do so may lead to penalties. At the same time, mark allocation for class participation is difficult to implement in large classes. Importantly, these initiatives should contribute to 
the final mark; otherwise it would be difficult to enforce such initiatives. Implementing these initiatives often leads to some logistical problems, for example monitoring attendance in a large class situation. In this regard, students sign attendance registers during the lecture and sufficient registers should be provided to avoid loss of lecturing time. Due to the fact that it is difficult to award marks for participation for large classes, the researcher opted to use unannounced quizzes and this initiative is discussed below.

\subsection{Unannounced quizzes}

In this study, unannounced quizzes were used as a teaching and learning initiative to encourage students to attend class. Due to their nature, unannounced quizzes are written randomly during lecture periods without giving students the exact date of when the quizzes are scheduled to be written. Students were advised during the introductory lecture about the nature of the unannounced quizzes and that they would be written at any time during their lecture periods. Constant reminders were made by the lecturer, in an effort to encourage students to prepare to write these quizzes at any time during the course of the semester. Unannounced quizzes were adopted for several reasons. These reasons are discussed below from both the students' and the lecturer's perspective.

Firstly, from a student perspective, students are encouraged attend lectures. Secondly, students are urged to study and revise their module material regularly, which in turn improves their chances of passing the module. Thirdly, unannounced quizzes have a long term benefit in that once students get into the habit of studying one module regularly; the chances are that these students will apply the same studying principles in other modules that they are registered for. This technique reduces students' study work loads during preparation for both exams and class tests. Additionally, the regular study of module material helps students to identify areas of concerns before it is too late. Moreover, students are encouraged to study module material in advance and be attentive in class because these quizzes could be written at the end of the lecture period. Thus, understanding the fact that these quizzes are written randomly, equips and prepares students' mindsets for the learning mode. Minds that are willing to learn give a different dimension to teaching and learning and encourages students' participation during lectures. Class discussions become lively and interesting. From the lecturer's perspective, unannounced quizzes provide constant feedback in terms of assessing the knowledge acquired by the students. This assists the lecturer in assessing levels of understanding and identifying ways of reinforcing difficult concepts, to the benefit of the students.

The use of unannounced quizzes as a teaching and learning initiative is not without flaws. For example, unannounced quizzes increase the lecturer's administration work load which includes the invigilation of these quizzes. Additionally, as different students have different learning styles other complementary methods of assessment should be used. Also, a student's final mark could be affected, especially if s/he misses a quiz. One way of dealing with such a challenge is for only some of the written quizzes to contribute to students' final marks, for example the highest two marks out of four quizzes that were completed. Another possible solution is for the lecturer to accommodate students with genuine reasons for missing a lecture. This gives rise to another problematic question, "what is a genuine reason for missing a lecture?" In this case, lecturers should use their discretion and if the need arises, supporting documents should be requested to reduce the risk of students abusing this system.

\subsection{Module background}

The initiative described in this paper was adopted during the 2012 academic year at the University of KwaZulu-Natal, Pietermaritzburg Campus. The teaching initiative was implemented in a second year Bachelor of Commerce compulsory module which is offered in both semesters of the academic year. Both semesters run for 16 weeks. Semester one commences in mid February and semester 2, the last week in July. Approximately $70 \%$ of the students registered for this module during both semesters were registered for a Bachelor of Commerce degree (specializing in two of the following majors: marketing, business finance, economics, management, supply chain management and human resources management). The remaining $30 \%$ of the students were registered for either a Bachelor of Social Science, a Bachelor of Arts or a Bachelor of Science degree as either a compulsory or as an elective module, depending on their choice of major. The module was comprised of one weekly 90 minute lecture period continued over a 13 week period. The module did not include tutorials for this module. Lecture attendance is encouraged, but not mandatory. To try to encourage students to attend lectures and improve their academic performance, students were given three quizzes and only the best two of these quizzes were used to calculate the student's final mark. In line with the best teaching practices, the module outline, lecture slides and additional notes were posted online on the Moodle learning site under the appropriate module website prior to the beginning of the semester. The number of students registered for this module in 2011 was 335 and 
150 for the first and second semester, respectively. During the period of this study in 2012, 350 students were registered during the first semester and 120 students were registered during the second semester.

\subsection{Administration of unannounced quizzes}

The administration of the unannounced quizzes was the same during the duration of the research project (i.e. two semesters). During the introductory lecture period, students were informed that unannounced quizzes would form part of their assessment criteria and would contribute to their final term mark. Generally, most students attend the first lecture of the semester because critical information is given and an overview of the module is discussed during this lecture. The background and the motivation for utilizing unannounced quizzes were also presented to the students. All queries regarding unannounced quizzes were attended to. The information on unannounced quizzes was also included in the module outline, a hard copy of which was distributed to the students in addition to an electronic copy which was made available to students before the start of lectures. Students were informed that these quizzes would be written randomly during the course of the semester, meaning that students would be required to study their module material regularly. Students were also informed that there were no make-up quizzes, which implies that a student would obtain no mark for missing the unannounced quiz. However, students who had valid reasons for missing the quiz (such as illness, lecture clashes, etc) were accommodated provided they submitted evidence to support their case. On several occasions the students were reminded about the use of unannounced quizzes as an assessment method. Unannounced quizzes consisted of 10 multiple choice questions and the duration of these quizzes was 15 minutes. These questions were taken from the previous chapters that had been covered in class.

For validity purposes, the module was organized as follows:

a) The lecturer was the same for both semesters.

b) During lecture periods, students were required to sign an attendance register on a weekly basis.

c) Due to the large classes, additional manpower was utilized for the invigilation of the unannounced quizzes.

d) The module content and the presentation thereof was fundamentally the same during both semesters. The only difference was that more recent examples and current news items were used in class.

e) The method of assessment was the same for both semesters when the initiative was utilized. The assessment method was as follows: two class tests worth $28 \%$, two unannounced quizzes worth $5 \%$ and a comprehensive final examination worth $67 \%$ of the final mark.

f) The final examination was graded without reference to the identity of the students. The examination cover page which includes the student number and student's signature was not referred to until the final marks were released.

The above assessment methods were fundamentally the same during both semesters in terms of the duration and the structure of the class tests, spot tests and the final examination. All tests consisted of multiple choice questions. The examination consisted of two sections. Section 1 consisted of multiple choice questions and section 2 of essay questions. Students were coached on answering essay questions and practice essay questions were provided during the course of the semester. Submission of practice essays was not compulsory. Students were given an option to either peer review their practice essays with fellow students or discuss these with the lecturer.

\section{Research Methods}

This study is exploratory and mixed methods were used to collect data over two semesters of 2012 academic year. Prior to embarking on this article, ethical clearance was obtained from UKZN's ethics committee. Three sources of data were used namely; observations; a questionnaire survey; and the university student data base. Observations were conducted by the lecturer and notes were recorded. The questionnaire mainly collected information about the students' perceptions of the use of unannounced quizzes. The questionnaires were distributed to students during the last lecture of the module. Prior to empirical data collection, both a letter of introduction and a consent form were handed to respondents. Respondents were made aware of the purpose of the research and were assured of their anonymity when completing the questionnaire.

In other words, participation in the survey was voluntary and students were not required to identify themselves on the questionnaire. A total of 199 completed questionnaires were received for the two semesters, representing a response rate of $42.23 \%$. The last lecture is normally set aside for clarifying any issues regarding the examination structure, module content and, most importantly, the completion of lecture evaluations. Students were provided with ample time to complete the questionnaire during the lecture and the completion of questionnaires was not compulsory. The completed 
questionnaires were coded and the responses captured using SPSS. Descriptive statistics and content analysis were used to analyze data. The characteristics of the sample are discussed next.

Table 1: Sample description

\begin{tabular}{|l|c|c|c|}
\hline \multicolumn{1}{|c|}{ Characteristics } & Frequency & Percentage (\%) & Cumulative percentage \\
\hline Gender: & 110 & 55.28 & 52.28 \\
Females & 89 & 44.72 & 100 \\
Males & 55 & 27.64 & 27.64 \\
\hline Age: & 106 & 53.27 & 80.91 \\
Below 20 years & 33 & 16.59 & 97.49 \\
$21-25$ years & 5 & 2.5 & 100 \\
$26-30$ years & 16 & 8.04 & 8.04 \\
Above 31 years & 146 & 73.37 & 81.41 \\
\hline Race: & 32 & 16.08 & 100 \\
Whites & 5 & 2.51 & 64.82 \\
Black African & 129 & 64.82 & 95.98 \\
Asians "Indians" & 62 & 31.16 & 100 \\
Mixed race "Coloureds" & 8 & 4.02 & \\
\hline Qualification (Degree): & & & \\
Bachelor of Commerce & & \\
Bachelor of Social Science / Bachelor of Arts & & \\
Bachelor of Science & &
\end{tabular}

In terms of the gender of the respondents, the majority (55.28\%) were females, while $44.72 \%$ were males. As for the age range of the respondents, the majority (53.27\%) of the students were aged between $21-25$ years. This was followed by the "Below 20 years" age group which constituted $27.64 \%$ of the sample. The $26-30$ years age category constituted $16.59 \%$ of the students. The "Above 31 years" age group made up only $2.5 \%$ of the sample. Regarding the race of the students, the majority (73.37\%) were Black Africans, while students of Asian origin ("Indians") constituted $16.08 \%$ of the group. A total of of $8.04 \%$ of the students were whites and the remaining $2.51 \%$ of the sample identified themselves as being mixed race ("Coloured"). In terms of the qualifications that the students were pursuing: $64.82 \%$ were studying towards a Bachelor of Commerce degree; $31.16 \%$ were studying towards a Bachelor of Social Science degree; and the remaining $4.02 \%$ were pursuing a Bachelor of Science degree. The empirical findings of the study are presented and discussed in the next section.

\section{Results and Discussions}

The research results are organized into three key themes. First, the discussion on whether unannounced quizzes enhance class attendance is presented. This is followed by the discussion of the relationship between class attendance and module pass rate. Lastly, the students' perceptions of the use of unannounced quizzes as a teaching and learning initiative are presented.

\subsection{Unannounced quizzes enhance class attendance}

The use of unannounced quizzes is an initiative that is seen to encourage class attendance (Rodgers, 2002), especially when these results contribute to the final module mark. The empirical findings reveal that lecture attendance improved significantly compared to the previous years where unannounced quizzes were not used. These results are presented in Table 2.

Table 2: Class attendance before and after the administration of unannounced quizzes

\begin{tabular}{|c|c|c|c|c|}
\hline & \multicolumn{2}{|c|}{ Before the administration of unannounced quizzes } & \multicolumn{2}{|c|}{ After the administration of unannounced quizzes } \\
\hline Period & 2011 Semester 1 & 2011 Semester 2 & 2012 Semester 1 & 2012 Semester 2 \\
\hline Average attendance & $63.23 \%$ & $43.67 \%$ & $89.97 \%$ & $91.23 \%$ \\
\hline
\end{tabular}


Table 2 depicts the average class attendance for the students before and after the introduction of unannounced quizzes. The average class attendance decreased from $63.23 \%$ to $43.67 \%$ during semester 1 and semester 2 of 2011 . With the introduction of unannounced quizzes in 2012, the average class attendance increased to $89.97 \%$ and $91.23 \%$ during the first and second semester of 2012, respectively. These results indicate that class attendance more than doubled with the introduction of unannounced quizzes. The empirical findings implicitly reveal that the use of unannounced quizzes enhances class attendance. These findings are in line with Devadoss and Foltz (1996) who argue that such initiatives have a significant, positive impact on class attendance. Although class attendance improved, one could argue that it is difficult to assess whether learning was taking place or not.

An increased number of filled seats in lecture theatres or $100 \%$ lecture attendance do not mean that learning is taking place because physical presence and intellectual involvement are two different issues (Rodgers, 2002). There is a possibility that some students attended lectures merely because they did not want to miss the quizzes. On the other hand, however, it could be argued that because students attended class in anticipation of writing a quiz, learning could have taken place, with their knowledge base being enhanced before and during the lecture. In order to encourage student interaction during the lecture, different class activities were implemented.

The use of unannounced quizzes also encouraged students to pay attention in class because they were unsure of when the quizzes would be written, and were aware that lecture material covered during the lecture could also form part of the quiz, if administered at the end of the lecture. Therefore, it can be assumed that unannounced quizzes encouraged the students to revise their work regularly because of their anticipation of writing a quiz test.

Observations also reveal that in as much as unannounced quizzes encouraged students to attend lectures, this initiative was not suitable for all students, particularly those who do not like to attend lectures. During the semesters under review, it was observed that there was always a group of students who would come to class just in time for the quiz. Over time, it was discovered that there was an organized group of students who would take turns to attend lectures. The student "on duty" had the responsibility of informing members of the organized group of students to rush to class as and when the quizzes were about to be written. This communication was sent via the use of cellular phones and social networks (SMS, BBM, WhatsApp etc). This use of technology (cell phones) in class brings in a new dimension to modern day teaching that needs to be taken into consideration.

Some benefits were noted as a result of the initiative. Communication between the lecturer and students improved significantly. The lecturer was privileged to get to know some students beyond the class, which is very rare in a large class situation. For example, some students would email the lecturer in advance if they were going to miss class explaining their reasons. Some of the reasons cited included death in the family, illness and clashes of test. Thus, the lecturer had the opportunity to gain insight into some of the challenges that negatively affect the students' performance. Below are three examples of emails that were sent by students.

\footnotetext{
"Dear ....., May I be excused from today's lecture because my marketing class test is clashing with my lecture period".

"Hello ......, I am sorry I walked out during yesterday's lecture because I was not feeling well".

"Dear ...., I will not be able to attend tomorrow's lecture because I have an appointment with the doctor".
}

These extracts reveal that some of the students developed an improved sense of responsibility. In such cases, these students would be given an overview of the concepts covered in class during their absence. If there was a quiz written during their absence, a make-up quiz would be arranged for them at a later date, unknown to the students. For example, the lecturer would email the student requesting him/her to come and see her as soon as possible or to see her at the end of the lecture period. Irrespective of the challenges in the administration of this initiative, a sense of responsibility and accountability was instilled in some students. This behaviour is desirable, considering that these students are the future leaders of South Africa. The discussion on whether class attendance improves module pass rate is presented next.

\subsection{Class attendance improves module pass rate}

The study also examined whether class attendance had an impact on the module overall pass rate. These results are depicted in Table 3. 
Table 3: Module overall pass rate before and after administration of unannounced quizzes

\begin{tabular}{|c|c|c|c|c|}
\hline \multirow[b]{2}{*}{ Period } & \multicolumn{2}{|c|}{$\begin{array}{l}\text { Results before the administration of } \\
\text { unannounced quizzes }\end{array}$} & \multicolumn{2}{|c|}{$\begin{array}{c}\text { Results after the administration of } \\
\text { unannounced quizzes }\end{array}$} \\
\hline & $\begin{array}{c}2011 \\
\text { Semester } 1 \\
\end{array}$ & $\begin{array}{c}2011 \\
\text { Semester } 2 \\
\end{array}$ & $\begin{array}{c}2012 \\
\text { Semester } 1 \\
\end{array}$ & $\begin{array}{c}2012 \\
\text { Semester } 2 \\
\end{array}$ \\
\hline Average class attendance & $63.23 \%$ & $43.67 \%$ & $89.97 \%$ & $91.23 \%$ \\
\hline Overall module pass rate & $69.63 \%$ & $41.38 \%$ & $89.12 \%$ & $90.97 \%$ \\
\hline Average class mark & $56.02 \%$ & $44.49 \%$ & $62.13 \%$ & $63.99 \%$ \\
\hline Class mean range & $50 \%-59 \%$ & $40 \%-49 \%$ & $60 \%-69 \%$ & $60 \%-69 \%$ \\
\hline$\%$ of students with distinction (i.e. $75 \% \leq$ ) & $11 \%$ & $3 \%$ & $15.45 \%$ & $15.28 \%$ \\
\hline
\end{tabular}

Note: Overall pass rate only includes the main examination results. Supplementary examination results are excluded.

Table 3 indicates that before the unannounced quizzes were introduced, the module pass rate decreased from $69.63 \%$ in semester one of 2011 to $41.38 \%$ during the second semester of 2011 . When unannounced quizzes were introduced during the 2012 academic year, the overall pass rate for the module doubled. The module pass rate increased to $89.12 \%$ and $90.97 \%$ during semester one and semester two of 2012, respectively. These results reveal that the use of unannounced quizzes to encourage class attendance can be seen to improve the module overall pass rate. These figures are similar to the average class attendance of students during the duration of the study. Based on these two sets of figures, it could be argued that average class attendance for a module somehow predicts the overall module pass rate. This implies that the lecturer could somehow predict the overall module pass rate.

Further analysis of the research results indicate that not only did the overall module pass rate improve, but the quality of results also improved. Thus, the students' average class mark improved significantly from $44.49 \%$ in the second semester of 2011 to $62.13 \%$ and $63.99 \%$ during semester one and semester two of 2012, respectively. In addition, the mean class pass mark shifted from the $40 \%-49 \%$ range in semester 2 of 2011 to the $60 \%-69 \%$ range during semester 1 and 2 of 2012. The number of students with distinctions also increased fivefold, from 3\% in semester 2 of 2011 to approximately 15\% during the two semesters of 2012. These results clearly indicate two critical issues; an improvement in the quantity or number of students successfully completing the module; and the quality of student results.

The findings are in agreement with a large body of literature which postulates that class attendance has an impact on students' performance (e.g. Rodgers, 2002; Massingham \& Herrington, 2006; Nyamapfene, 2010). Observations by the lecturer also indicate that class participation improved and the number of students asking questions in class improved. In most cases, if students excel in one module, there is a tendency that the same students are motivated to improve their performance in other modules, thereby increasing their overall pass grades.

This information is critical, especially within the South African context where there is a high dropout rate of students from institutions of higher learning. When students successfully complete their studies within the required minimum time, it results in significant savings in the government coffers. These resources could be utilized elsewhere in the development of the South African economy. The successful increase in pass rate could also be seen to have an impact on the number of students who take up postgraduate studies. The fact that the quality of results increased, implies that more students would qualify to further their education to master's and doctoral degree level. The students' perceptions of the use of unannounced quizzes is presented and discussed next.

\subsection{Students' perceptions of the use of unannounced quizzes}

With regard to student's perceptions of the use of unannounced quizzes as a teaching initiative that enhances class attendance, the majority (84.9\%) of the students agreed that unannounced quizzes were helpful, while only $15.1 \%$ were against the initiative. From the students who believed that unannounced quizzes were helpful, three key themes emerged. These themes are displayed in Table 4.

Table 4: Student's perceptions of the benefits of unannounced quizzes

\begin{tabular}{|l|c|}
\hline \multicolumn{1}{|c|}{ Themes } & Frequency (\%) \\
\hline $\begin{array}{l}\text { Spot tests encouraged me to study on a regular basis which helped to reduce the work load during tests and } \\
\text { exams. They also helped me to identify problematic areas early, thereby encouraging me to seek guidance. }\end{array}$ & 41 \\
\hline $\begin{array}{l}\text { Spot tests encouraged me to revise my course material before the lecture, as well as reading in advance. } \\
\text { They also helped me to prepare for class tests and the exams well in advance. }\end{array}$ & 48 \\
\hline Spot tests are so useful, they should be used for other modules as well. & 15 \\
\hline Spot tests encouraged me to attend lectures. & 8 \\
\hline
\end{tabular}


The results in Table 4 reveal that the use of unannounced quizzes was beneficial to students beyond encouraging them to attend classes, as evidenced by the frequency with which the theme was identified. Some students expressed in discussion that they were of the view that the use of unannounced quizzes was beneficial beyond the module, in that they applied the same studying technique in other modules. Thus, students got into the habit of revising their study material regularly, which is a desirable habit among university students. Below is a sentiment from a student who felt that unannounced quizzes should be encouraged among institutions of higher learning in order to improve the university throughput ratio.

"It's a good strategy to assist students who are failing at university".

Although the use of unannounced quizzes yielded positive results, some students were not happy with this arrangement. These sentiments are presented in Table 5.

Table 5: Student's perceptions of the disadvantages of the use of unannounced quizzes

\begin{tabular}{|l|c|}
\hline \multicolumn{1}{|c|}{ Theme } & Frequency (\%) \\
\hline $\begin{array}{l}\text { I don't like surprises, I prefer to be told in advance when I will be writing the unannounced quizzes so } \\
\text { that I prepare accordingly. }\end{array}$ & 5 \\
\hline Naturally, I hate attending lectures.... spot tests forced me to do what I would not normally do. & 4 \\
\hline $\begin{array}{l}\text { As a university student, I would like to have the right exercise my freedom. I don't want to be forced } \\
\text { to attend lectures. I am an adult. }\end{array}$ & 2 \\
\hline
\end{tabular}

In as much as students like to exercise their freedom, many students end up abusing such rights. Some students indicated that they dislike surprises. However, informing them of when the unannounced quizzes were to be written would have defeated the objective of encouraging lecture attendance. Such actions encourage students to learn only when they are required to do so. Students should be given an opportunity to construct knowledge willingly. Similarly, students who do not like to attend lectures should consider distance learning, which would perhaps suit their personality better.

\section{Conclusion}

In conclusion, the aim of this research study was to establish whether the use of unannounced quizzes enhances class attendance; to examine the relationship between class attendance and module pass rate; and to explore students' perceptions on the use of unannounced quizzes as a teaching and learning initiative. The findings reveal that class attendance improved significantly during the period under study and that class attendance had improved the overall module pass rate. Additionally, the quality of students' marks improved significantly. The majority of students (84.9\%) perceived that the use of unannounced quizzes as a teaching and learning initiative enhances class attendance and that these quizzes were helpful. Some students even indicated that they got into the habit of revising the study material regularly for other modules and felt that it was a good strategy to assist students who are failing at university.

The main limitation to the insights provided by this study is that only two sets of students who were registered for a second year undergraduate module were included in the study and therefore the findings cannot be generalized to all students at the University of KwaZulu-Natal, or to all students in general. For further research, a similar study could be repeated using a different set of students registered for other compulsory second year modules in order to explore whether the results would be consistent with the results of this study. This study could be replicated with other undergraduate management courses and could also include the lecturers' perspectives.

The results of this study contribute to enhancing undergraduate teaching and learning strategies adopted by universities. It explores a teaching and learning initiative that encourages class attendance and responds to the call of new thinking on how universities could increase their throughput ratio. Lastly, the findings of this research are expected to revive future debate on how to effectively impact knowledge in a large class situation. As Benjamin Franklin appropriately put it: "Tell me and I forget. Teach me and I remember. Involve me and I learn". 


\section{References}

Biggs, J. (1999). Teaching for Quality Learning at University. What the student does. Buckingham, UK: Open University Press.

Butler-Adam, J. (2013). The national budget 2013/2014: Education, the environment and science and technology. South African Journal of Science, 109(1/2):1. [Online] Available at http://dx.doi.org/10.1590/sajs.2013/a012 (March 1, 2014).

Cleary-Holdforth, J. (2007). Student non-attendance in higher education: A phenomenon of student apathy or poor pedagogy? Level 3 : Dublin Institute of Technology online publication, (5). [Online] Available: http://level3.dit.ie/html/issue5/cleary-holdforth/cleary_ holdforth.pdf (March 3, 2014).

Department of Education. (1999). Higher Education Institutional Plans: An Overview of the First Planning Phase 1999/2001. Pretoria: Government Printers.

Devadoss, S. \& Foltz, J. (1996). "Evaluation of factors influencing student class attendance \& performance". American Journal of Agricultural Economics, 78:499-507.

Education for All (EFA). (2013). Country Progress Report: South Africa. [Online] Available: http://www.education.gov.za/LinkClick.aspx?fileticket=TZ4Cx\%2BcnCzk\%3D\&tabid=36 (February 10, 2014).

Franklin, B. (No Date). Benjamin Franklin quotes. [Online] Available: http://brainyquote.com (March 10, 2014).

Gatherer, D. \& Manning, F. C. R. (1998). Correlation of examination performance with lecture attendance: A comparative study of first year biological science undergraduates. Biochemical Education, 23:121-123.

Gillard, E., Saunders, S., Terblanche, J. \& Sukel, M. (2012). A review of four case studies in restructuring the South African Higher Education System. African Higher Education Research, 1-33. [Online] Available: http://ahero.uwc.ac.za/index.php? module=cshe\&action=viewtitle\&id=cshe_842 (March 25, 2014).

HSRC. (2008). High university drop-out rates: a threat to South Africa's future. [Online] Available: http://www.hsrc.ac.za/uploads/pageContent/1088/Dropout\%20rates.pdf (February 28, 2014).

Jungic, V., Kent, D. \& Menz, P. (2006). Teaching large math classes: Three instructors, one experience. International Electronic Journal of Mathematics Education, 1(1):1-15.

Leufer, T. \& Cleary-Holdforth, J. (2010). Reflections on the experience of mandating lecture attendance in one school of nursing in the Republic of Ireland. All Ireland Journal of Teaching in Higher Education, 2(1):18.1-18.13.

Massingham, P. \& Herrington, T. (2006). Does attendance matter? An examination of student attributes, participation, performance and attendance. Journal of University Teaching \& Learning Practice, 3(2):83-103.

Mahadeo, J. D. (2012). Teaching and learning in large classes: overcoming the challenges with technology. International Journal of Innovations in Business, 1(2):151-160.

Ministry of Education. (2002). Transformation and Restructuring: A New Institutional Landscape for Higher Education. [Online] Available: http://www.dhet.gov.za/LinkClick.aspx?fileticket=180xu4C\%2F\%2FUA\%3D\&tabid=92\&mid=495 (March 20, 2014).

Mulryan-Kyne, C. (2010). Teaching large classes at college and university level: Challenges and opportunities. Teaching in Higher Education, 15(2):175-185.

Nyamapfene, A. (2010). Does class attendance still matter? Engineering Education, 5(1):64-74.

Nzimande, B. E. (2014). Speech by the minister of higher education on the launch of the white paper for post education and training, Pretoria, Unisa, 16 January 2014. [Online] Available: http://www.dhet.gov.za/LinkClick.aspx?fileticket=1\%2f\%2f3OtzLth0\% 3d\&tabid=1166 (March 16, 2014).

Rodgers, J. R. (2002). Encouraging tutorial attendance at University did not improve performance. Australian Economic papers, 41(3):255-266

Stanca, L. (2006). The effects of attendance on academic performance: Panel data evidence for introduction to microeconomics. Journal of Economic Education, 251-266.

Tella, A. (2007). University of Botswana undergraduates' uses of the internet: implications on academic performance. Journal of Educational Media \& Library Sciences, 45(2):161-185.

University of KwaZulu-Natal. (No Date). [Online] Available: www.ukzn.ac.za (March 11, 2014).

Van Walbeek, C. 2004. Does lecture attendance matter? Some observations from a first year Economics course at the University of Cape Town. South African Journal of Economics, 72(4):861-882.

Visser, H. \& van Zyl, D. (2013). Assessment of academic readiness to achieve student success and retention. South African Journal of Higher Education, 27(2):330-352.

Weller, M. (2004). Models of large-scale e-learning. JALN, 8(4):83-92. 